\title{
Structural and Transport Properties of Binary Mixtures of Deep Eutectic Solvent (Ethaline) with Primary Alcohols: A Molecular Dynamics Study
}

\author{
Kishant Kumar ${ }^{\mathrm{a}, *}$, Aditya Sinha ${ }^{\mathrm{b}}$, Anand Bharti ${ }^{1}$ \\ ${ }^{a}$ Department of Chemical Engineering, National Institute of Technology Warangal, \\ Warangal, Telangana, India-506004 \\ ${ }^{b}$ Department of Chemical Engineering, Birla Institute of Technology Mesra, Ranchi, \\ Jharkhand, India-835215
}

\begin{abstract}
Deep eutectic solvents (DESs) are classified as the green solvents which are considered as an alternative to volatile organic solvents. In this work, the thermophysical, structural and transport properties of binary mixtures of DES ethaline (choline chloride $(\mathrm{ChCl})+$ ethylene glycol (etgly) at a molar ratio of 1:2) with primary alcohols (methanol/ethanol) are studied using molecular dynamics (MD) simulations. Density of various concentration of alcohol in DES obtained from the MD simulation are compared with experimental data, which is found to be in a good agreement i.e. \%ARD value in the range of 0-7\%. Structural properties such as radial distribution function (RDF), co-ordination number $(\mathrm{CN})$ and $\mathrm{H}$-bond were analysed from the trajectories of MD simulation. It was revealed from the peak of RDF and visualization from the trajectories of $\mathrm{MD}$ simulation that the alcohol strongly interacts with ethylene glycol and chloride ion. Existence of several H-bond types was identified in the binary mixture of ethaline and alcohol. In addition, average number of H-bond was found to be highest for etgly- $\mathrm{Cl}^{-}$system for both methanol and ethanol mixture with DES. Self-diffusion coefficient was evaluated for the methanol and ethanol, which was found to be dependent on the concentration of added alcohol. It is interesting
\end{abstract}

\footnotetext{
${ }^{*}$ Corresponding authors

Email addresses: kishant@nitw.ac.in (Kishant Kumar), abharti@bitmesra.ac.in (Anand Bharti)
} 
to note that the self-diffusion coefficient of alcohol in binary mixture of ethaline + alcohol increases by $\sim 25$ times at an alcohol mole fraction of 0.9 than at 0.1 . Therefore, an appropriate amount of alcohol in DES could be considered as a best choice as a green solvent with all required thermophysical properties in process industry.

Keywords: Deep Eutectic Solvent, Alcohol, Radial distribution function, Molecular Dynamics Simulation, Hydrogen bonding network, Self-diffusion coefficient

\section{INTRODUCTION}

In the last few years, scientists, researchers, and engineers working in academia and industries are following the concept of green engineering for the design and development of new products and processes. They are also working on im-

5 proving the existing processes to promote the sustainability and lower the toxic and hazardous content in the environment for a better human health without sacrificing efficiency, safety, and economics [1]. Solution-based chemistry and processes are not far behind in this race. Green solvents are being developed to replace the toxic, flammable, and high volatile organic solvents. Over the last two decades, room temperature ionic liquids (RTILs) have gained much attention. They are fascinating high-performance compounds. RTILs have very low vapor pressure, wide range of temperature for liquid existence, and high thermal and chemical stability. RTILs are termed as designer solvents as their properties can be tuned by the suitable selection of cations and anions.

15 These exciting properties led to a multidisciplinary study of RTILs in several areas such as catalysis, material science, chemical engineering, electrochemistry, medicinal chemistry, environmental science, and many more at both industrial and laboratory scales $[2,3,4,5,6,7,6,9,10,11$. Despite all these advantages, multi-step synthesis, high cost, and high viscosity make RTILs unattractive for native to RTILs have attracted much attention. DESs are prepared by simply 
mixing hydrogen bond donor (HBD) and hydrogen bond acceptor (HBA). While DESs and RTILs possesses distinct chemical properties but they have almost similar physical properties such as wide liquid-range, low vapor pressure, and nonflammability. DESs have several benefits over RTILs such as their biocompatibility, relatively less expensive, easy to prepare, and easy availability. Due to these properties, DESs have been investigated for different applications in diverse areas $113,14,15,16,17,18,19,20$. For the development of DESs based processes, understanding of DESs thermodynamics and their physicochemical 30 properties of mixed DESs with common organic solvents such as water, alcohol or alkanes are of keen interest. It is relevant to study and explore the structure, thermal, physical and chemical properties of the DESs mixtures, which changes upon mixing with conventional solvents. Extensive studies have been carried out to understand the properties of mixtures of DESs and water experimentally

35 as well as theoretically but very few studies were carried out for binary mixture of alcohols and DES.

Choline chloride (ChCl) based DESs mainly Reline $[\mathrm{ChCl}(1)$ : Urea (2)] and ethaline [ChCl (1) : Ethylene Glycol (etgly) (2)] have been widely investigated solvents because they are cheap and easy to prepare. Only few experimental 40 and computational work have investigated the mixtures of ethaline with either methanol, ethanol, 1-butanol, or DMSO. For example, Leron et al. have experimentally measured the densities and refractive indices of the mixture of ethaline and water at atmospheric pressure over the temperature range of 298.15-333.15 K. Obtained excess molar volumes from the experimental density data was found 45 to be negative at all the temperatures which indicated the presence of strong interactions between water and ethaline in the mixtures [21. Lerol et al. have further measured the densities of ethaline and water mixture over high pressure range (0.1-50 MPa). The calculated excess molar volumes were again found to be negative at all temperatures and pressures. They observed that the calcu50 lated excess molar volumes decreased with increase in temperature and pressure, which may be possible due to the dependence of the hydrogen bonding (H-bond) strength on temperature, which resulted to decreases in the molecular 
distance upon increase in temperature 22]. Yadav et al. have experimentally measured the densities of ethaline and water mixture in the temperature range of 283.15-363.15 $\mathrm{K}$ and calculated the excess molar volumes of the aqueous mixtures. It was again found to be negative which hint the presence of stronger interactions, preferably because of the strong $\mathrm{H}$-bond between ethaline and water 23. Harifi-Mood et al. measured the density, electrical conductivity and viscosity of binary mixtures of ethaline and dimethyl sulfoxide at the condition of atmospheric pressure and temperatures within a range of 308.15 to 363.15 K. The mixture exhibited negative deviation from ideality for excess molar volumes which suggests H-bond interactions between ethaline and DMSO [24]. Gajardo-Parra et al. studied the volumetric behaviour of mixtures of ethaline and 1-butanol. They found negative excess volumes and thus concluded the stronger interactions (possibly because of strong H-bond) between ethaline and 1-butanol in the solution. 25. Recently, Haghbakhsh et al. have reported the volumetric properties of ethaline and methanol mixture at atmospheric pressure over the temperature range of 283.15 - $323.15 \mathrm{~K}$. The calculated density from the experiment was used to measure the different volumetric properties such as excess, partial and excess partial molar volumes, where they have reported negative values for all of these excess molar volumes. The negative value suggests the strong interaction between the cross molecules compared to the interactions between two identical molecules in pure solution (pure ethaline or methanol solution). Therefore, they have suggested that the H-bond in the solution mixture are forming a network in such a way that the central position is possessed by the ethaline while methanol are distributed around it 26]. Similarly, Haghbakhsh et al. have also investigated the mixture density of ethaline and ethanol within a temperature range of $293.15-333.15 \mathrm{~K}$ and at an atmospheric pressure. Different excess and partial molar volumes were calculated and correlation was established using the results from the density measurement. They found all the excess volume properties to be negative, which indicates the strong H-bond interaction between the cross species i.e. ethaline and ethanol[27].

All the above reported experimental work mainly measures the density of 
the binary mixture and based on that calculates the excess properties. But it doesn't give any microscopic view/molecular level understanding of the liquid mixture. Therefore, it is necessary to perform molecular simulation to understand the liquid structure and various interactions in the mixture at atomic level. Only few molecular simulation work has been reported so far for the mixture of DES/alcohol/water. Kaur et al. investigated the effect of water on the structural and transport properties of ethaline. They observed that the original arrangement of ethaline components continue to exists upto $40 \mathrm{~mol} \%$ of water, while the transition from ethaline phase to water phase occurs between the 62.5 and $76.9 \mathrm{~mol} \%$ of water. They have concluded that the chloride ion acts as a bridge of H-bond between the choline cation and etgly, which eliminates upon addition of water, where chloride ion is more solvated to water molecules 28. Celebi et al. have performed molecular dynamics simulations of aqueous ethaline solutions. At a low mass fraction of water $(<5 \%)$, the H-bond network in ethaline solution doesn't change significantly, while further increase in water content (upto $40 \%$ by mass) causes the significant amount of H-bond elimination between etgly and chloride ion change followed by a complete aqueous phase upon further addition of water 29.

In this work, we have carried out atomistic molecular dynamics simulation of ethaline + methanol and ethaline + ethanol systems for entire composition range at $303.15 \mathrm{~K}$. This study provides a detailed description on the structural and transport properties of binary mixtures of ethaline.

\section{COMPUTATIONAL DETAILS}

\subsection{Force field Details}

All atom force field for DES ( i.e. ethaline) and organic solvent (methanol, ethanol) considered in this work are obtained from the study of Acevado et al [30] and Julian et al 31] respectively, while former forcefield is the refined version of OPLS-AA and later is the original version of OPLS-AA for organic liquids. All non-bonded as well as bonded potential parameters are provided in the Table 
S1 through S4 of supplementary information. The non-bonded potential was calculated as the sum of electrostatic and Lennard-Jones (LJ) potentials using Equation 1. The cross term in the LJ potential parameter such as epsilon (well depth $\left.\left(\epsilon_{i j}\right)\right)$ and epsilon $\left.\left(\sigma_{i j}\right)\right)$ were evaluated using the geometric combining rules i.e., $\epsilon_{i j}=\left(\epsilon_{i i}+\epsilon_{j j}\right)^{0.5}$ and $\sigma_{i j}=\left(\sigma_{i i}+\sigma_{j j}\right)^{0.5}$ respectively. The calculation of electrostatic terms is computationally expensive therefore Ewald summation techniques were employed using the particle-mesh Ewald scheme 32] (PME), where $4^{\text {th }}$ order interpolation was applied. Non-bonded parameter for inter and intra molecular geometry was not treated explicitly, therefore contribution from the non-bonded potential were ignored for the 1-2 and 1-3 connected atoms, while the contribution from 1-4 connected atoms were scaled to 0.5 . It is also important to note that the non-bonded interaction was excluded between atom type of $\mathrm{OH}$ and $\mathrm{OG}$ of etgly which can participate in intra-hydrogen bonding. The bonded potential such as bond, angle, dihedral terms are given by the harmonic bonded function, harmonic angular function and Fourier series in the form of four cosine terms as described by the Equation 2 while the improper term was also defined as the same Fourier series. The atom types of the studied molecule in this work are depicted in the Figure 1 .

$$
\begin{array}{r}
\mathrm{U}_{\mathrm{nb}}=\sum_{\mathrm{i}>\mathrm{j}}\left[\frac{\mathrm{q}_{\mathrm{i}} \mathrm{q}_{\mathrm{j}}}{4 \pi \varepsilon_{0} \mathrm{r}_{\mathrm{ij}}}\right]+\sum_{\mathrm{i}>\mathrm{j}} 4 \epsilon_{\mathrm{ij}}\left[\left(\frac{\sigma_{\mathrm{ij}}}{\mathrm{r}_{\mathrm{ij}}}\right)^{12}-\left(\frac{\sigma_{\mathrm{ij}}}{\mathrm{r}_{\mathrm{ij}}}\right)^{6}\right] \\
\mathrm{U}_{\mathrm{b}}=\sum_{\text {bonds }}\left[\frac{1}{2} \mathrm{k}_{\mathrm{b}}\left(\mathrm{r}-\mathrm{r}_{\mathrm{e}}\right)^{2}\right] \\
+\sum_{\text {angles }}\left[\frac{1}{2} k_{\theta}\left(\theta-\theta_{e}\right)^{2}\right]+ \\
\sum_{\text {dihedrals }+ \text { improper }}\left[\frac { 1 } { 2 } \left[C_{1}(1+\cos (\Phi))+C_{2}(1-\cos (2 \Phi))\right.\right. \\
+C_{3}(1+\cos (3 \Phi))+C_{4}(1-\cos (4 \Phi))
\end{array}
$$

where $\mathrm{U}_{n b}, \mathrm{U}_{b}$ are the non bonded and the bonded potential respectively. $\mathrm{q}_{i}$ and $\mathrm{q}_{j}$ are the partial charges on the $\mathrm{i}^{\text {th }}$ and $\mathrm{j}^{\text {th }}$ atoms respectively. $\mathrm{r}_{i j}$ is the distance between $\mathrm{i}^{\text {th }}$ and $\mathrm{j}^{\text {th }}$ atoms respectively. $\epsilon$ and $\sigma$ are the well 
depths and van der Waals radii respectively. $\mathrm{k}_{b}, \mathrm{k}_{\theta}$ and C's represent force constant for bond, angle and Fourier constant respectively. $\mathrm{r}_{e}$ and $\theta_{\mathrm{e}}$ defines the eqilibrium bond length and angle values. The four term parameters are provided for calculation of Fourier dihedral potential but these terms were converted into six term parameter for calculation of potential using Ryckaert-Bellemans functional form because of more computationally efficient (see the section 5.5 of the GROMACS manual 33 ]).

\subsection{Molecular Dynamics Simulation Details}

Molecular dynamics simulations were carried out for the mixture of ethaline and alcohol at different molar ratio ranging from 0 to 1 as shown in the Table 1. In addition, each system was also simulated at four different temperature ranging from 293.15 to $323.15 \mathrm{~K}$ with an equal interval of $10 \mathrm{~K}$. Recent release of GROMACS 2020.2 version was used for MD simulation in this work 34]. Initially, the optimized structures of single molecule of HBA and HBD were obtained from the work of Acevado et al [30, where they have optimised the structure of the molecule using density-functional theory. First of all, the system were prepared using the packmol program[35], which is a tool to generate the initial configuration of the molecular system. A fixed set of 100 molecule of ethaline $(100 \mathrm{ChCl}$ and 200 etgly) was considered in this work, where an appropiate number of alcohol (ethanol and methanol) molecules were added in a large box of $50 \AA$ in order to explore the effect of varying mole fraction of alcohol in ethaline (see Table 1). The composition of the systems studied in this work is depicted in the Table 1, where concentration was calculated based on mass fraction $\left(w_{R O H}\right)$ and three different types of molar concentration viz. $x_{R O H}, x_{R O H}^{\prime}$ and $x_{R O H}^{\prime \prime}$. The definition of the different types of concentration are given by the Equation $3,4,5$ and 6 , where $w_{R O H}$ is calculated as the ratio of alcohol mass to the total mass, $x_{R O H}$ is the ratio of moles of alcohol and total moles (where $\mathrm{ChCl}$ and Etgly are assumed to be different species), $x_{R O H}^{\prime}$ and $x_{R O H}^{\prime \prime}$ was computed by assuming $\mathrm{ChCl}$ in dissociated form and $\mathrm{ChCl}+$ Etgly as one component respectively. Four different types of concentra- 
tions corresponding to the simulated number of molecules were presented in this

$\left.\mathrm{w}_{\mathrm{ROH}}=\frac{\left(\mathrm{N}_{\mathrm{ROH}}\right)\left(\mathrm{M}_{\mathrm{ROH}}\right)}{\left(\mathrm{N}_{\mathrm{Ch}^{+}}\right)\left(\mathrm{M}_{\mathrm{Ch}^{+}}\right)+\left(\mathrm{N}_{\mathrm{Cl}^{-}}\right)\left(\mathrm{M}_{\mathrm{Cl}^{-}}\right)+\left(\mathrm{N}_{\mathrm{Etgly}}\right)\left(\mathrm{M}_{\mathrm{Etgly}}\right)+\left(\mathrm{N}_{\mathrm{ROH}}\right)\left(\mathrm{M}_{\mathrm{ROH}}\right)}\right]$

Generally, in experiment, concentration is evaluated by assuming the HBDs to be the pseudo-component, which is given by the Equation 6. The obtained structure after packing into a box were allowed to undergo energy minimization to remove any unwanted overlapping in the structure. A minimum potential energy of the best possible conformation of the molecule were achieved using the steepest-descent minimization method with a maximum force converging criteria of $1000.0 \mathrm{~kJ} \times \mathrm{mol}^{-1} \times \mathrm{nm}^{-1}$ within the 50000 steps. Thereafter, a MD simulation in the NPT ensemble for 2 ns were carried out at $298 \mathrm{~K}$ followed by an annealing simulation. In the annealing simulation, the system was allowed to undergo sudden increase in the temperature upto $500 \mathrm{~K}$ and cooled down at $298 \mathrm{~K}$ for three cycles in the time interval of $300 \mathrm{ps}$. The annealing protocol in NVT ensemble was conducted in order to ensure the best possible conformation in the range of 293.15 to $323.15 \mathrm{~K}$. Finally, a MD simulation of total 40 ns were carried out for all the systems in the NPT ensemble at an ambient pressure condition. Temperature of the system was controlled using the velocity rescale 36 with stochastic term while the pressure was maintained using the Berendsen pressure coupling technique 37. A time constant of 1.0 ps was used for coupling of temperature and pressure of the system with an isotropic assumption (pressure coupling will prevail on every wall of the box equally). Periodic boundary condition was applied in all the directions with LJ and short range electrostatic cutoff of $14 \AA$ in all the MD simulations. All the $\mathrm{H}$ atom containing bonds were constrained using the LINCS algorithm and the Newton's equation of motion was solved after every 1.0 fs of time interval. The simulation was further extended to additional time of 60 ns for calculation of diffusion coefficient in diffusive regime.

$$
(3)
$$



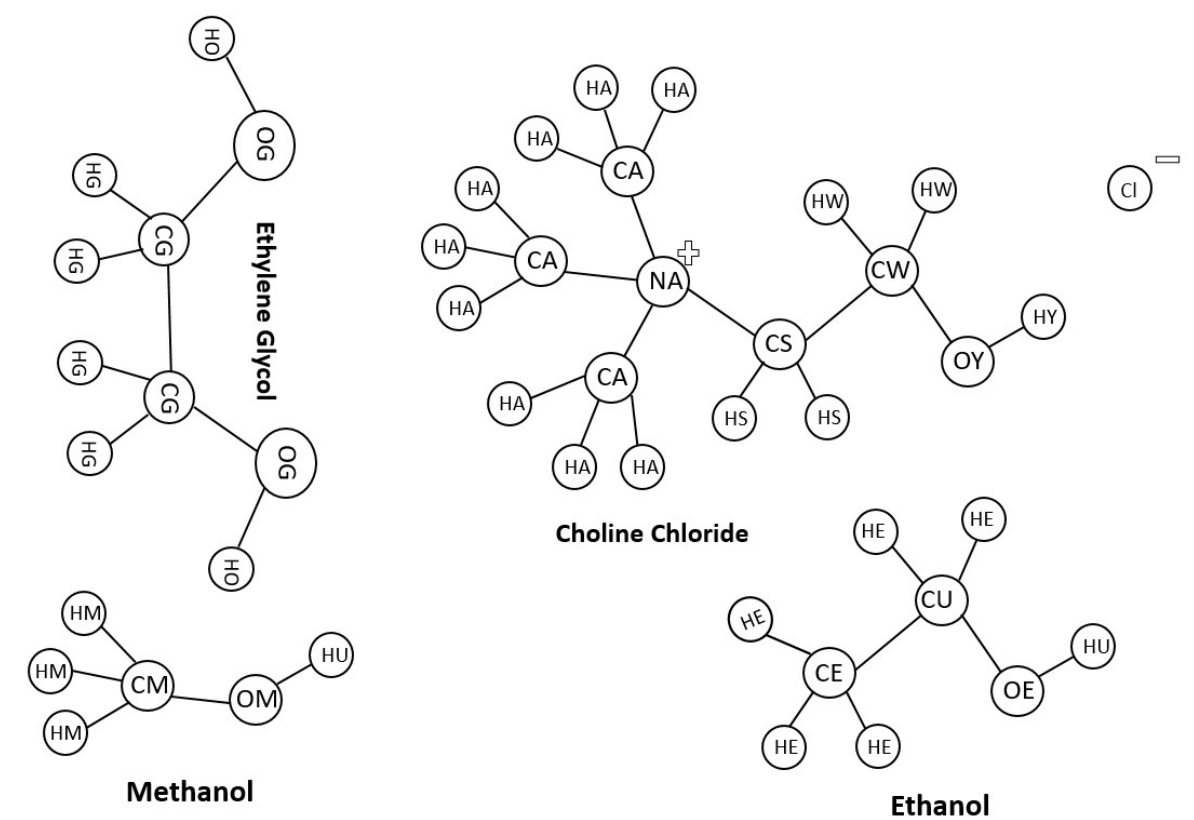

Figure 1: Description of anions/cations and neutral molecule based on atom-type used in this work

$$
\begin{gathered}
\mathrm{x}_{\mathrm{ROH}}=\frac{\mathrm{N}_{\mathrm{ROH}}}{\mathrm{N}_{\mathrm{Chcl}}+\mathrm{N}_{\text {Etgly }}+\mathrm{N}_{\mathrm{ROH}}} \\
\mathrm{x}_{\mathrm{ROH}}^{\prime}=\frac{\mathrm{N}_{\mathrm{ROH}}}{\mathrm{N}_{\mathrm{Ch}}++\mathrm{N}_{\mathrm{Cl}}+\mathrm{N}_{\text {Etgly }}+\mathrm{N}_{\mathrm{ROH}}} \\
\mathrm{x}_{\mathrm{ROH}}^{\prime \prime}=\frac{\mathrm{N}_{\mathrm{ROH}}}{\mathrm{N}_{\text {ethaline }}+\mathrm{N}_{\mathrm{ROH}}}
\end{gathered}
$$

\section{Results and Discussion}

\subsection{Simulated Density vs. Experimental Density}

A comparison has been done between the molecular dynamics predicted density values with the experimental density values for ethaline-methanol and 195 ethaline-ethanol mixtures at four different temperatures 293.15, 303.15, 313.15 
Table 1: System compositions studied in this work, where abbreviations for CCEM and CCEE are $\mathrm{ChCl}+$ etgly + Methanol and $\mathrm{ChCl}+$ etgly + Ethanol respectively. In addition, 0.1, 0.3, 0.5, 0.7 and 0.9 represents mole fraction of the added alcohol. $N_{C h C l}$ (Number of molecules of $\mathrm{ChCl})=100$ and $N_{U r e a}($ Number of molecules of urea $)=200$

\begin{tabular}{cccccc}
\hline & $N_{R O H}$ & $w_{R O H}$ & $x_{R O H}$ & $x_{R O H}^{\prime}$ & $x_{R O H}^{\prime \prime}$ \\
\hline ethaline & - & - & - & - & - \\
CCEM (0.1M) & 11 & 0.01 & 0.04 & 0.03 & 0.10 \\
CCEM (0.3M) & 43 & 0.05 & 0.13 & 0.10 & 0.30 \\
CCEM (0.5M) & 100 & 0.11 & 0.25 & 0.20 & 0.50 \\
CCEM (0.7M) & 233 & 0.22 & 0.44 & 0.37 & 0.70 \\
CCEM (0.9M) & 900 & 0.52 & 0.75 & 0.70 & 0.90 \\
Methanol & 1000 & - & - & - & - \\
CCEE (0.1E) & 11 & 0.02 & 0.04 & 0.03 & 0.10 \\
CCEE (0.3E) & 43 & 0.07 & 0.13 & 0.10 & 0.30 \\
CCEE (0.5E) & 100 & 0.15 & 0.25 & 0.20 & 0.50 \\
CCEE (0.7E) & 233 & 0.29 & 0.44 & 0.37 & 0.70 \\
CCEE (0.9E) & 900 & 0.61 & 0.75 & 0.70 & 0.90 \\
Ethanol & 1000 & - & - & - & - \\
\hline
\end{tabular}


Table 2: Comparison of simulated density and experimental density for various methanol composition in ethaline at a pressure of $0.1 \mathrm{MPa}$

\begin{tabular}{|c|c|c|c|c|}
\hline Methanol mole fraction & Simulated Density $\left(\mathrm{kg} / \mathrm{m}^{3}\right)$ & RMSD (simulation) & Experimental Density 26] $\left(\mathrm{kg} / \mathrm{m}^{3}\right)$ & $\% \mathrm{ARD}$ \\
\hline & \multicolumn{4}{|c|}{$\mathrm{T}=293.15 \mathrm{~K}$} \\
\hline 0.10 & 1109.27 & 4.67 & 1105.90 & 0.30 \\
\hline 0.30 & 1095.05 & 4.08 & 1071.70 & 2.13 \\
\hline 0.50 & 1073.74 & 4.12 & 1025.00 & 4.54 \\
\hline 0.70 & 1033.85 & 3.78 & 958.80 & 7.26 \\
\hline \multirow[t]{2}{*}{0.90} & 929.28 & 3.02 & 860.70 & 7.38 \\
\hline & \multicolumn{4}{|c|}{$\mathrm{T}=303.15 \mathrm{~K}$} \\
\hline 0.10 & 1100.88 & 4.31 & 1100.10 & 0.07 \\
\hline 0.30 & 1087.10 & 4.17 & 1065.60 & 1.97 \\
\hline 0.50 & 1065.74 & 4.04 & 1018.50 & 4.43 \\
\hline 0.70 & 1024.89 & 3.93 & 951.60 & 7.15 \\
\hline \multirow[t]{2}{*}{0.90} & 919.93 & 3.11 & 852.30 & 7.35 \\
\hline & \multicolumn{4}{|c|}{$\mathrm{T}=313.15 \mathrm{~K}$} \\
\hline 0.10 & 1092.68 & 4.41 & 1094.40 & -0.16 \\
\hline 0.30 & 1079.50 & 4.43 & 1059.50 & 1.85 \\
\hline 0.50 & 1057.66 & 4.22 & 1012.00 & 4.32 \\
\hline 0.70 & 1016.83 & 4.01 & 944.40 & 7.12 \\
\hline \multirow[t]{2}{*}{0.90} & 910.17 & 3.14 & 844.00 & 7.27 \\
\hline & \multicolumn{4}{|c|}{$\mathrm{T}=323.15 \mathrm{~K}$} \\
\hline 0.10 & 1084.87 & 4.46 & 1088.80 & -0.36 \\
\hline 0.30 & 1071.32 & 4.50 & 1053.40 & 1.67 \\
\hline 0.50 & 1049.47 & 4.24 & 1005.60 & 4.18 \\
\hline 0.70 & 1008.03 & 4.04 & 937.30 & 7.02 \\
\hline 0.90 & 900.15 & 3.19 & 835.50 & 7.18 \\
\hline
\end{tabular}


Table 3: Comparison of simulated density and experimental density for various ethanol composition in ethaline at a pressure of $0.1 \mathrm{MPa}$

\begin{tabular}{|c|c|c|c|c|}
\hline Ethanol mole fraction & Simulated Density $\left(\mathrm{kg} / \mathrm{m}^{3}\right)$ & RMSD (simulation) & Experimental Density[27] $\left(\mathrm{kg} / \mathrm{m}^{3}\right)$ & $\% \mathrm{ARD}$ \\
\hline & \multicolumn{4}{|c|}{$\mathrm{T}=293.15 \mathrm{~K}$} \\
\hline 0.10 & 1106.34 & 4.20 & 1098.40 & 0.72 \\
\hline 0.30 & 1088.15 & 3.98 & 1048.70 & 3.63 \\
\hline 0.50 & 1059.21 & 4.01 & 993.20 & 6.24 \\
\hline 0.70 & 1009.87 & 3.79 & 925.00 & 8.40 \\
\hline \multirow[t]{2}{*}{0.90} & 905.978 & 2.71 & 843.30 & 6.92 \\
\hline & \multicolumn{4}{|c|}{$\mathrm{T}=303.15 \mathrm{~K}$} \\
\hline 0.10 & 1098.47 & 4.32 & 1092.60 & 0.54 \\
\hline 0.30 & 1079.58 & 4.30 & 1042.40 & 3.44 \\
\hline 0.50 & 1051.34 & 4.11 & 986.50 & 6.17 \\
\hline 0.70 & 1001.00 & 3.77 & 917.60 & 8.33 \\
\hline \multirow[t]{2}{*}{0.90} & 896.683 & 2.82 & 835.20 & 6.86 \\
\hline & \multicolumn{4}{|c|}{$\mathrm{T}=313.15 \mathrm{~K}$} \\
\hline 0.10 & 1090.77 & 4.56 & 1086.80 & 0.36 \\
\hline 0.30 & 1071.83 & 4.38 & 1036.30 & 3.31 \\
\hline 0.50 & 1043.01 & 4.03 & 979.90 & 6.05 \\
\hline 0.70 & 992.703 & 3.87 & 910.40 & 8.29 \\
\hline \multirow[t]{2}{*}{0.90} & 887.258 & 2.90 & 827.10 & 6.78 \\
\hline & \multicolumn{4}{|c|}{$\mathrm{T}=323.15 \mathrm{~K}$} \\
\hline 0.10 & 1082.94 & 4.41 & 1081.10 & 0.17 \\
\hline 0.30 & 1063.93 & 4.50 & 1030.20 & 3.17 \\
\hline 0.50 & 1034.93 & 4.41 & 0973.40 & 5.94 \\
\hline 0.70 & 984.392 & 3.97 & 0903.20 & 8.25 \\
\hline 0.90 & 877.539 & 2.98 & 0819.00 & 6.67 \\
\hline
\end{tabular}


and $323.15 \mathrm{~K}$. The density values are tabulated in Table 2 \& 3 . There is an excellent agreement for the alcohol-lean compositions while the agreement is fairly good for the alcohol-rich compositions.

\subsection{Radial Distribution Function(RDF) and Coordination Number $(C N)$}

first increases slightly and then decreases with increasing ethanol mole fraction. On an average 4.1 methanol molecules surround the choline ion at 0.1 methanol mole fraction which reduces to 1.5 at 0.9 methanol mole fraction. Similarly, On an average 3.7 ethanol molecules surround the choline ion at 0.1 ethanol mole 


\subsubsection{Interaction between chloride ion and alcohol}

Figure $2 \mathrm{~b}$ and Figure $4 \mathrm{~b}$ shows the RDF of methanol- $\mathrm{Cl}^{-}$and ethanol- $\mathrm{Cl}^{-}$ systems respectively. It is characterized by very intense first peak at $3.2 \AA$ and $3.8 \AA$ respectively. The methanol-chloride ion interaction mainly develops through HU atom of alcohol and chloride ion (Figure $3 \mathrm{a}$ and Figure $5 \mathrm{a}$ ) with maxima at $2.1 \AA$. The intensity of the peak for methanol- $\mathrm{Cl}^{-}$system (also HU$\mathrm{Cl}^{-}$) first increases and then decreases with increasing methanol composition while the intensity of peak continuously increases with increasing ethanol mole fraction in ethanol- $\mathrm{Cl}^{-}$system (also $\mathrm{HU}_{-} \mathrm{Cl}^{-}$). But all of them maintain their position in the whole composition range. The coordination number of alcohols around chloride ion is found to decrease with increase in alcohol concentration for both the systems. But compared to choline ion, only 0.8 methanol molecules surround the chloride ion at low methanol composition which reduces to 0.3 at high methanol composition. Similar trend is also observed in ethaline-ethanol slightly high compared to ethaline-methanol system. This clearly suggests that the alcohol molecules interact more strongly with choline ion in comparison to chloride ion.

\subsubsection{Interaction between ethylene glycol and alcohol}

RDFs of alcohol-etgly are shown in Figure 2r and Figure 4k. The RDFs are characterized by two peaks. The first intense peak is at $4.5 \AA$ and $4.7 \AA$ for methanol and ethanol systems respectively. The intensity of first peak decreases with increasing alcohol composition for both the systems while the position of the peak remains the same. The interaction between HU atom of alcohol and OG atom of etgly is responsible for the interaction between alcohol-etgly (Figure 3 ; and 5k) with maxima at $1.9 \AA$. The intensity of this peak increases with increasing methanol concentration while for ethanol system it first decreases and then incresaes. The coordination number of alcohols around etgly is found 
to decrease with increase in alcohol concentration for both the systems. But were identified for further analysis (see the Figure S1 of SI). Types of H-bond 

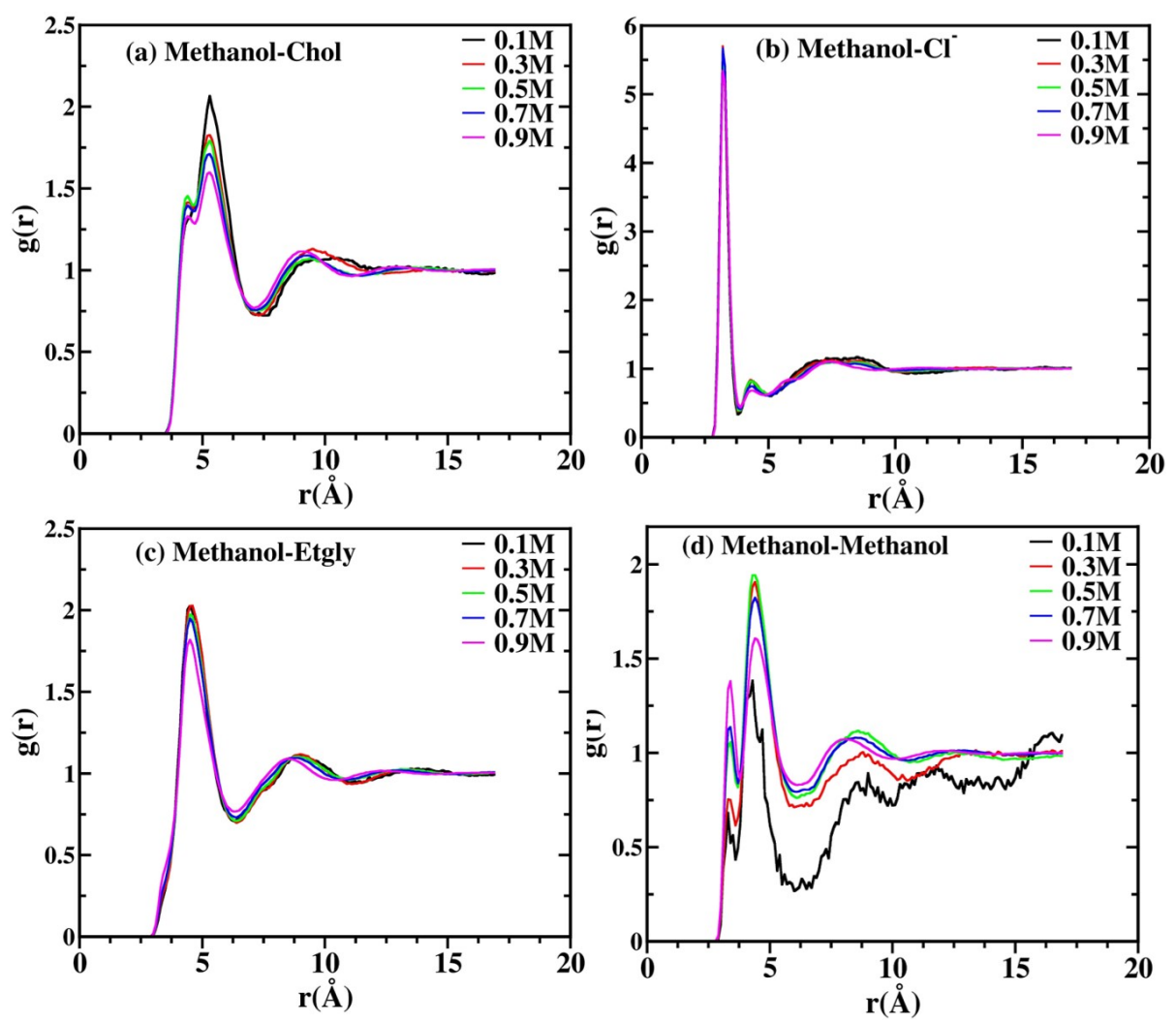

Figure 2: Center-of-mass RDF for (a) methanol-chol ${ }^{+}$, (b) methanol-Cl- ${ }^{-}$, (c) methanol-Etgly, and (d) methanol-methanol pairs in methanol-ethaline mixtures at $303.15 \mathrm{~K}$ and $0.1 \mathrm{MPa}$. 

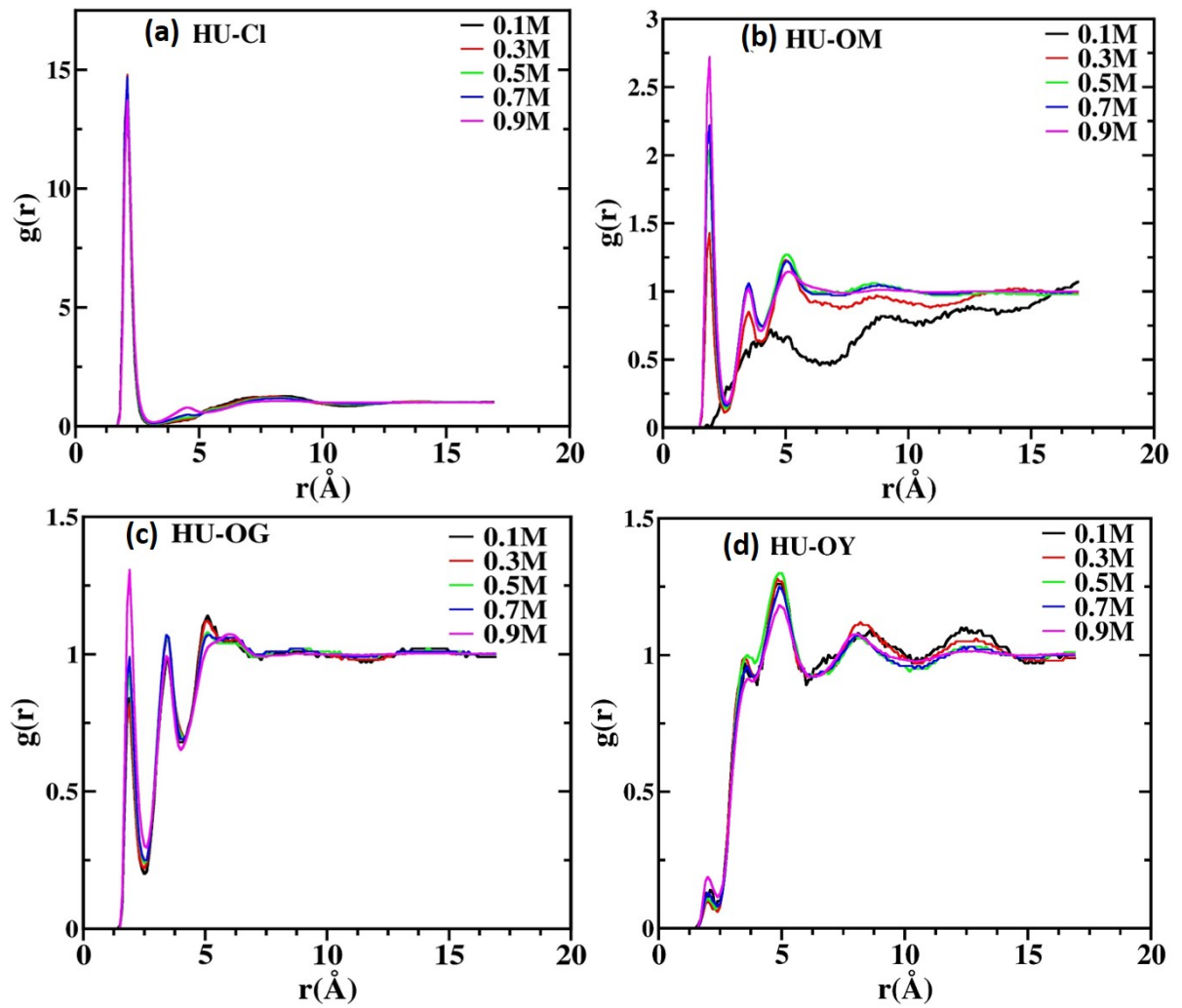

Figure 3: Atom-atom RDF for methanol-ethaline mixtures at $303.15 \mathrm{~K}$ and $0.1 \mathrm{MPa}$. 

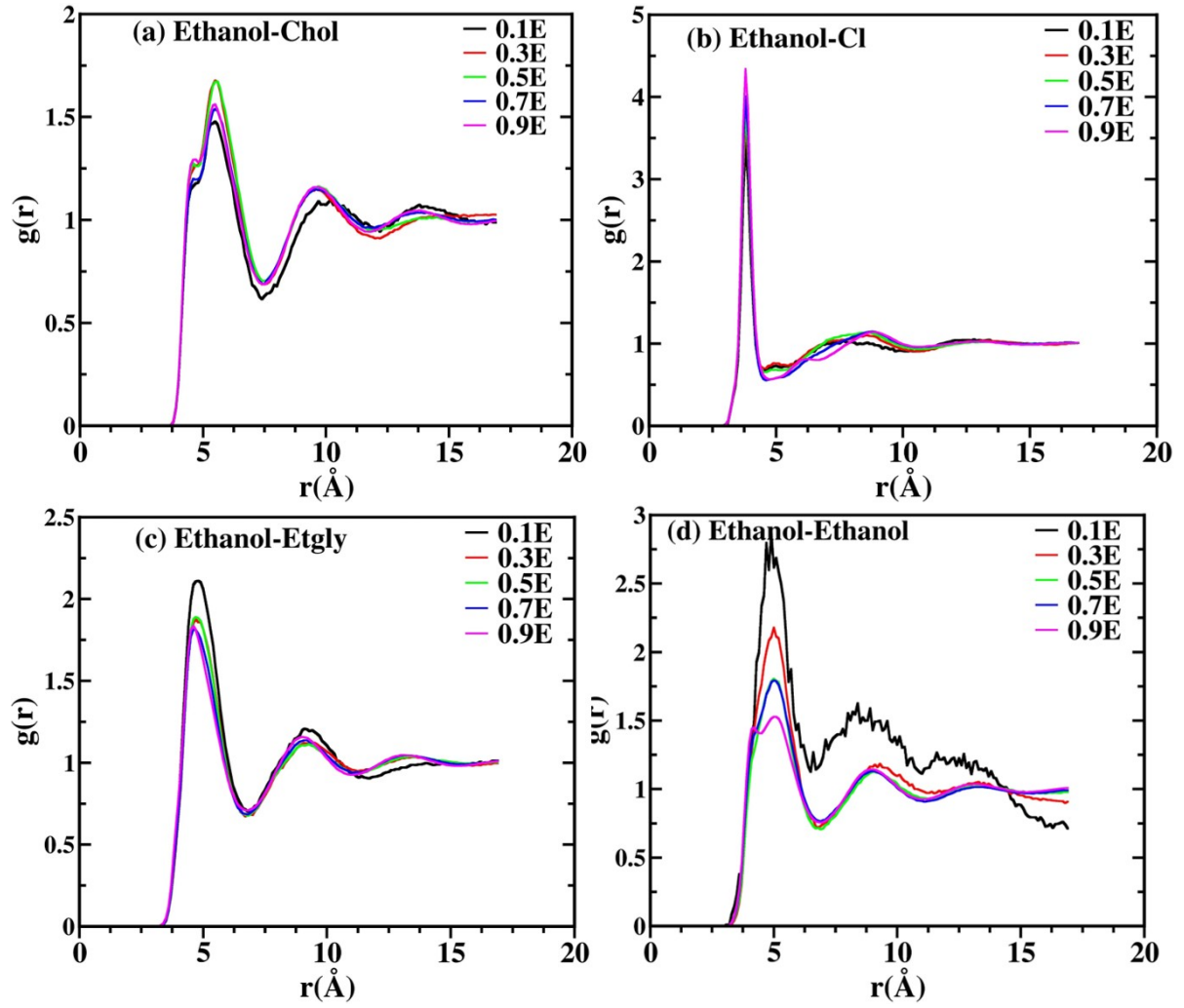

Figure 4: Center-of-mass RDF for (a) ethanol-chol ${ }^{+}$, (b) ethanol- $\mathrm{Cl}^{-}$, (c) ethanol-Etgly, and (d) ethanol-ethanol pairs in ethanol-ethaline mixtures at $303.15 \mathrm{~K}$ and $0.1 \mathrm{MPa}$. 

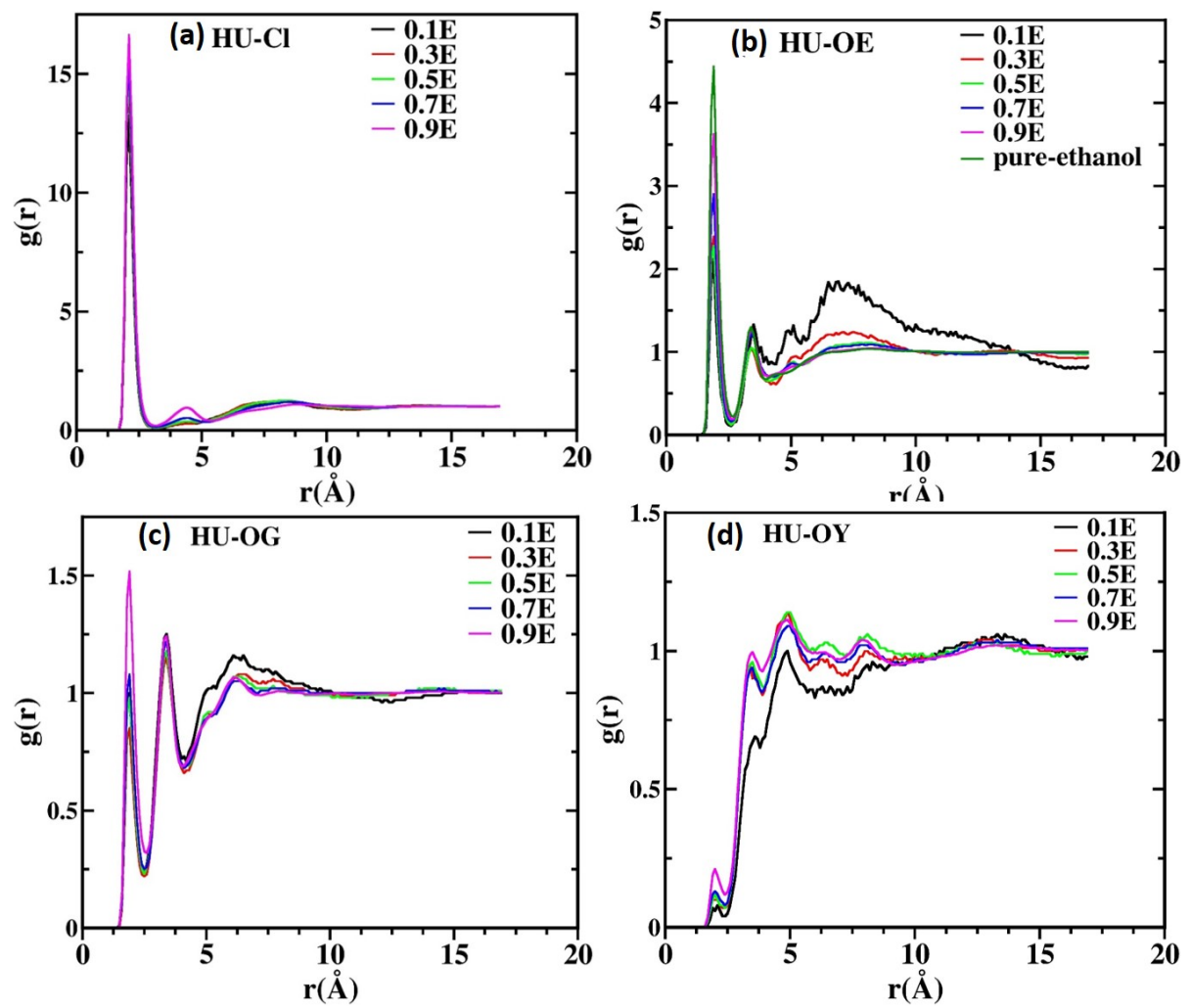

Figure 5: Atom-atom RDF for ethanol-ethaline mixtures at $303.15 \mathrm{~K}$ and $0.1 \mathrm{MPa}$. 

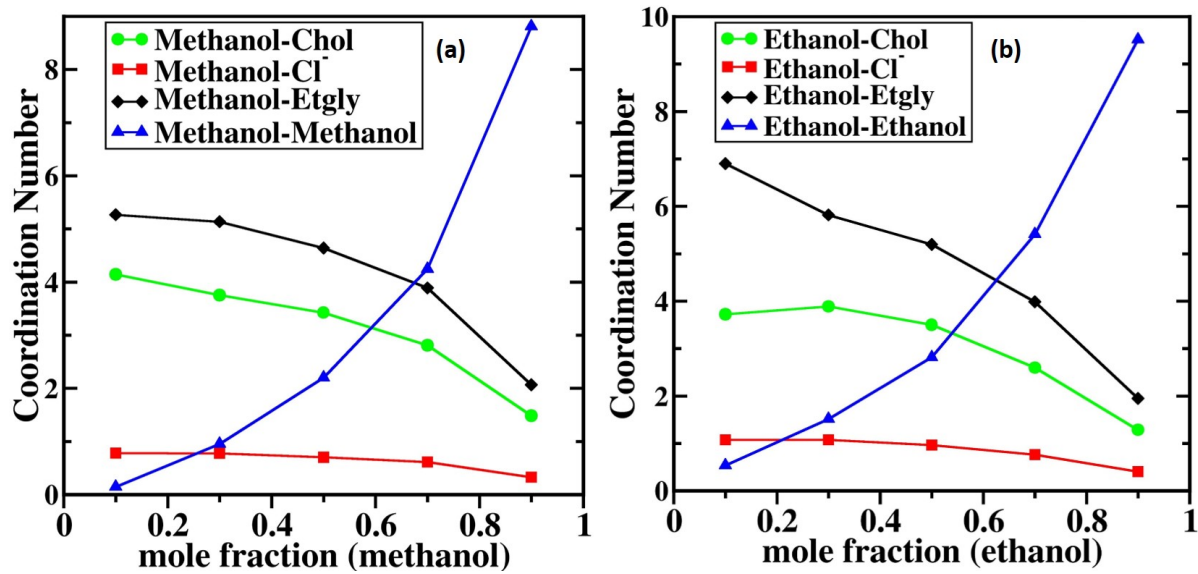

Figure 6: Coordination number (first solvation shell) for different chemical species around methanol and ethanol molecule, calculated from center-of-mass RDF reported in Figures 2 and 4 for methanol-ethaline and ethanol-ethaline mixtures respectively at $303.15 \mathrm{~K}$ and 0.1 MPa. $1^{\text {st }}$ solvation shell is defined by the first minima in the corresponding RDF.

are as follows a) between OG (Etgly) and OX (methanol or ethanol), both as donor atom b) between OG and OG, both as donor atom c) between OX and $\mathrm{Cl}^{-}$, only $\mathrm{OX}$ as donor d) between $\mathrm{OX}$ and $\mathrm{OX}$, both as donor atom e) $\mathrm{OG}$ and $\mathrm{Cl}^{-}$, only $\mathrm{OG}$ as donor atom. The atom types are shown in the Figure 1 and definition of donor and acceptor atom is discussed in the Figure S1 of the SI. Formation of H-bond among the ethyl alcohol, methanol and chloride ions was confirmed by visualization (see Figure 8). Thereafter, H-bond per donor molecule between hydrogen bonded with polar oxygen atom i.e. OG (as donor) and chloride ion (as acceptor) were calculated and observed to be the highest among other types of H-bond(see Figure 7). It is quite interesting to note that upon increasing the concentration of alcohol, the H-bond per unit donor molecule (i.e. methanol) between the alcohol groups increases significantly while the vice versa is true for H-bond per donor molecule between the OG (ethylene glycol) and $\mathrm{Cl}^{-}$(chloride ion), which is clearly depicted in the Figure 7 (a). Likewise, ethanol also contains only one hydroxyl group where H-bonds persists in almost same arrangement as the case with methanol, which can be compared 

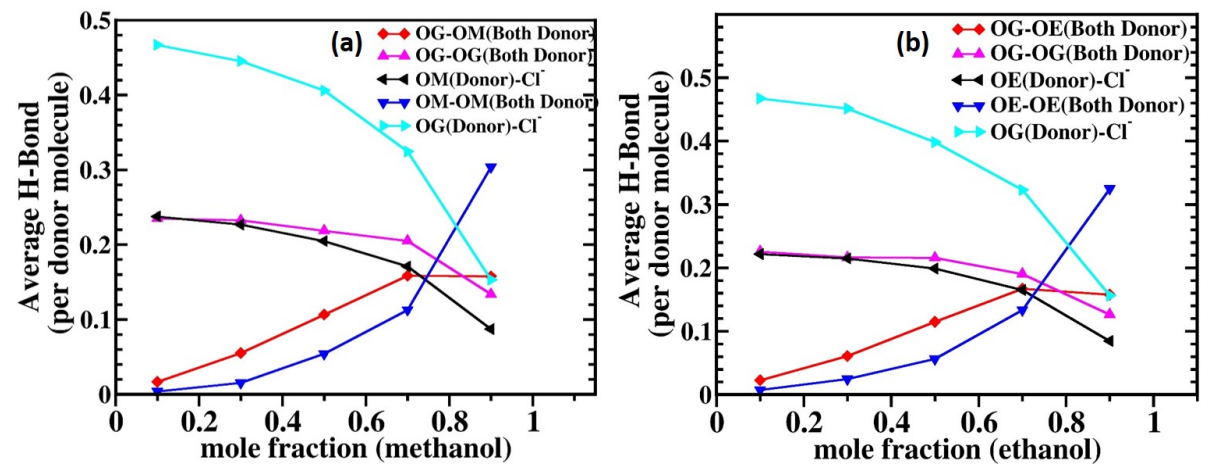

Figure 7: Average number of H-Bond per donor molecule for a) methanol and b) ethanol
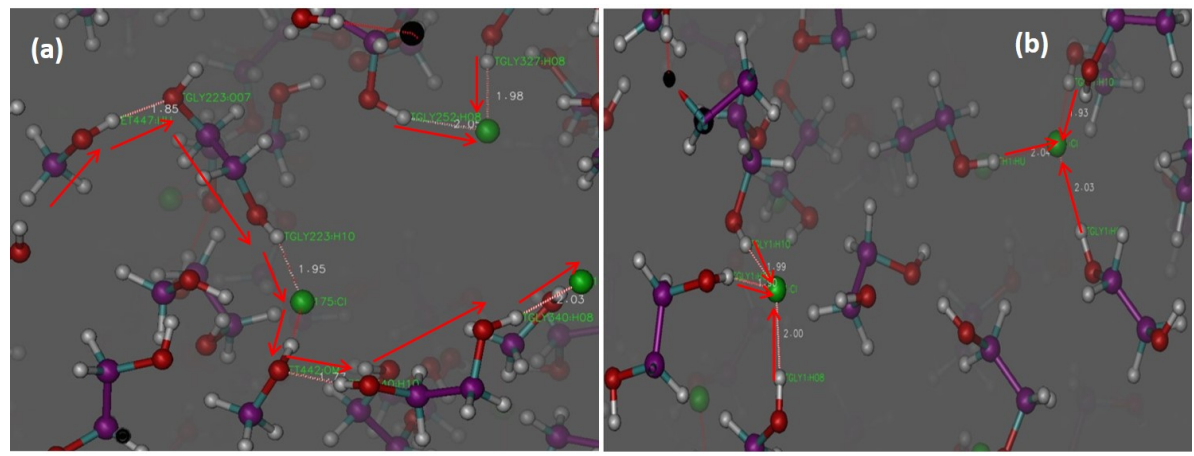

Figure 8: Snapshot shows the network of hydrogen bonds formed in the ethaline-alcohol solution a) methanol b) ethanol

from the Figure 7 (a) \& (b). The H-bond was observed to be almost constant upto an alcohol concentration of 0.5 , while decreases significantly upon further increasing the alcohol concentration. Similarly, H-bond between OG and OG (both as donor) decreases while the H-bond between OG and OM or OE (both as donor) increases upon increasing the alcohol concentration (see Figure 7 (a) \& (b)). H-bond between the oxygen of alcohol molecule and chloride ion was observed, which was found to be less pronounced than the H-bond between oxygen of etgly and chloride ion (see Figure 7 (a) \& (b)). 


\subsection{Diffusivity Calculation}

Dynamic properties are very important for industrial purposes. In this work, self-diffusion coefficients were calculated from the slope of the mean square dis-

310 represents self diffusivity, $\mathrm{N}$ represents total number of particles, $\vec{r}$ is the position vector of the particle, while $\mathrm{t}$ and $\Delta \mathrm{t}$ are the time and finite change in time respectively. Self-diffusion coefficients provide information of the dynamics of molecules in liquid mixtures. $D_{\text {self }}$ of methanol and ethanol are computed at a temperature and pressure of $303.15 \mathrm{~K}$ and $0.1 \mathrm{MPa}$ respectively for the alcohol mole fraction range of $0.1-0.9$. $\beta$ parameter was calculated according to Equation 8. where a value close to one was observed for all composition for except $0.1 \mathrm{M}$ (see Figure $\mathrm{S} 2$ of the SI). The choice of time region to locate the proper diffusive regime for the calculation of accurate diffusion coefficient from MD by several researchers [40, 41, 42. The calculation of diffusion coefficient was done in the time region where the $\beta$ value is found to be closer to one. Although the simulation was carried out at a temperature of $303.15 \mathrm{~K}$, where a diffusion coefficient of $3.07 \times 10^{-9} \mathrm{~m}^{2} / \mathrm{sec}$ and $1.273 \times 10^{-9} \mathrm{~m}^{2} / \mathrm{sec}$ for pure methanol and ethanol respectively was observed, which is found to be in close agreement with the experiment i.e. $2.415 \times 10^{-9} \mathrm{~m}^{2} / \mathrm{sec}$ and $1.075 \times 10^{-9} \mathrm{~m}^{2} / \mathrm{sec}$ for methanol 43 . and ethanol 44 respectively carried out at a temperature and pressure of 298.15 $\mathrm{K}$ and 0.1 MPa respectively. Diffusion coefficient of methanol/ethanol increases upon increase in the concentration of alcohol (methanol/ethanol) in ethaline.

Ethanol has lower diffusivity than methanol because of its larger size and strong van der Waals interaction. It has been investigated that the H-bond exists between the etgly and chloride ions, the H-bond network further extends upon addition of alcohol, where alcohols was observed to involve in H-bond with chloride ion as well as etgly (see Figure 7 , 8).

$$
\mathrm{D}_{\text {self }}=\frac{1}{6} \lim _{\mathrm{t}^{\prime} \rightarrow \infty} \frac{\mathrm{d}}{\mathrm{dx}}\left\langle\sum _ { \mathrm { i } = 1 } ^ { \mathrm { N } } \left[\overrightarrow{r_{i}}(\mathrm{t}+\Delta \mathrm{t})-\vec{r}_{i}(t)^{2}\right.\right.
$$


Table 4: Self diffusion coefficient $\left(10^{-11} \mathrm{~m}^{2} \mathrm{sec}^{-1}\right)$ of methanol and ethanol at $\mathrm{T}=303.15 \mathrm{~K}$ and $\mathrm{P}=0.1 \mathrm{MPa}$.

\begin{tabular}{cccc} 
mole fraction & Methanol diffusivity $\left(\mathrm{m}^{2} \mathrm{sec}^{-1}\right)$ & Ethanol diffusivity $\left(\mathrm{m}^{2} \mathrm{sec}^{-1}\right)$ & Time bound (ns) \\
\hline 0.10 & 4.38 & 2.87 & $5-13$ \\
0.30 & 7.56 & 4.65 & $5-15$ \\
0.50 & 12.68 & 7.80 & $5-15$ \\
0.70 & 29.09 & 16.14 & $5-15$ \\
0.90 & 110.84 & 51.82 & $5-15$ \\
\hline
\end{tabular}

$$
\beta(\mathrm{t})=\frac{\mathrm{d} \log _{10}\left\langle\left(\Delta \mathrm{r}(\mathrm{t})^{2}\right)\right\rangle}{\mathrm{d} \log _{10} \mathrm{t}}
$$

\section{CONCLUSION}

In this present study, MD simulations were carried out to investigate the thermo-physical, structural and transport properties of ethaline solution with varying concentration of alcohols (methanol and ethanol). Refined OPLS-AA force field was employed in order to accurately mimic the density observations from the experiment, where we have observed an excellent agreement with the experiment throughout the temperature range of 293.15-323.15K. RDF was computed between the COMs of two different species as well as between two different atom types. RDF analysis revealed stronger interaction between alcohol \& ethylene glycol, alcohol \& choline ion and alcohol \& chloride ion. These interactions are mainly through $\mathrm{HU}$ atom ( alcohol) \& OG atom (ethylene glycol) and between $\mathrm{HU}$ atom (alcohol) \& OY atom (choline ion) for methanol-ethaline and ethanol-ethaline respectively. Average $\mathrm{H}$-Bond was computed between the different possible sites, where we have observed the existence of five different types of $\mathrm{H}-\mathrm{B}$ ond which follows the order, $\mathrm{OG}-\mathrm{Cl}^{-}>\mathrm{OG}-\mathrm{OG} \sim \mathrm{OM} / \mathrm{E}-\mathrm{Cl}^{-}>\mathrm{OG}^{-}$ $\mathrm{OM} / \mathrm{E} \sim \mathrm{OM} / \mathrm{E}-\mathrm{OM} / \mathrm{E}$. In pure ethaline, a strong H-bond was observed between etgly and chloride ion $\left(\mathrm{OG}-\mathrm{Cl}^{-}\right)$. Addition of alcohol in the pure ethaline leads 
to decrease in average $\mathrm{H}$-Bond between $\mathrm{OG}_{-}-\mathrm{Cl}^{-}$while average $\mathrm{H}$-Bond between $\mathrm{OM} / \mathrm{E}-\mathrm{OM} / \mathrm{E}$ and $\mathrm{OG}-\mathrm{OM} / \mathrm{E}$ increases simultaneously. As the composition of alcohol increases, its self-diffusion co-efficient also increases, while self diffusion of methanol was observed to be twice higher than the ethanol possibly because of small van der Waals size. At high concentration of alcohol, the self-diffusion coefficient of alcohol was observed to be almost $\sim 25$ times higher than the value at low concentration, which indicates the possible modification of green solvent to improve the thermophysical properties for future industrial application.

\section{ACKNOWLEDGEMENTS}

Author is thankful to Science and Engineering Research Board (SERB) for financial support under the grant number EEQ/2020/000480. Author also wish to acknowledge the department of chemical engineering at National Institute of Technology Warangal, Telangana, India for supporting the research work conducted in the design and simulation laboratory.

\section{SUPPORTING INFORMATION}

Force field parameters, H-bond labels and $\beta$ parameter for diffusion calculation

\section{References}

[1] P. T. Anastas, J. B. Zimmerman, Peer reviewed: design through the 12 principles of green engineering (2003).

[2] S. Werner, M. Haumann, P. Wasserscheid, Ionic liquids in chemical engineering, Annual review of chemical and biomolecular engineering 1 (2010) 203-230.

375 [3] G. W. Meindersma, A. R. Hansmeier, A. B. de Haan, Ionic liquids for aromatics extraction. present status and future outlook, Industrial \& Engineering Chemistry Research 49 (16) (2010) 7530-7540. 
口 [4] J. P. Hallett, T. Welton, Room-temperature ionic liquids: Solvents for synthesis and catalysis. 2, Chemical Reviews 111 (5) (2011) 3508-3576, pMID: 21469639. arXiv:https://doi.org/10.1021/cr1003248, doi:10. $1021 / \operatorname{cr} 1003248$.

URL https : //doi .org/10.1021/cr1003248

[5] N. Adawiyah, M. Moniruzzaman, S. Hawatulaila, M. Goto, Ionic liquids as a potential tool for drug delivery systems, MedChemComm 7 (10) (2016) 1881-1897.

[6] M. Watanabe, M. L. Thomas, S. Zhang, K. Ueno, T. Yasuda, K. Dokko, Application of ionic liquids to energy storage and conversion materials and devices, Chemical reviews 117 (10) (2017) 7190-7239.

[7] Introduction: Ionic liquids, Chemical Reviews 117 (10) (2017) 66336635, pMID: 28535681. arXiv:https://doi.org/10.1021/acs.chemrev. 7b00246, doi:10.1021/acs.chemrev.7b00246.

URL https://doi .org/10.1021/acs . chemrev .7b00246

¿ [8] C. J. Clarke, W.-C. Tu, O. Levers, A. Bröhl, J. P. Hallett, Green and sustainable solvents in chemical processes, Chemical Reviews 118 (2)

395 (2018) 747-800, pMID: 29300087. arXiv:https://doi.org/10.1021/ acs.chemrev.7b00571, doi:10.1021/acs.chemrev.7b00571.

URL https://doi.org/10.1021/acs . chemrev.7b00571

[9] T. Welton, Ionic liquids: a brief history, Biophysical reviews 10 (3) (2018) $691-706$.

${ }_{400}^{0}[10]$ S. K. Singh, A. W. Savoy, Ionic liquids synthesis and applications: An overview, Journal of Molecular Liquids 297 (2020) 112038. doi:https://doi.org/10.1016/j.molliq.2019.112038.

घURL http://wWw.sciencedirect.com/science/article/pii/ S0167732219333719 
405

[11] F. Ren, J. Wang, F. Xie, K. Zan, S. Wang, S. Wang, Applications of ionic liquids in starch chemistry: a review, Green Chem. 22 (2020) 2162-2183. doi:10.1039/C9GC03738A.

URL http://dx.doi.org/10.1039/C9GC03738A

[12] W. Kunz, K. Häckl, The hype with ionic liquids as solvents, Chemical 410 cplett.2016.07.044

口 URL http://www.sciencedirect.com/science/article/pii/ S0009261416305346

[13] E. L. Smith, A. P. Abbott, K. S. Ryder, Deep eutectic solvents (dess) and 415 their applications, Chemical Reviews 114 (21) (2014) 11060-11082, pMID: 25300631. arXiv:https://doi.org/10.1021/cr300162p doi:10.1021/ cr300162p.

URL https://doi.org/10.1021/cr300162p

[14] L. Duan, L.-L. Dou, L. Guo, P. Li, E.-H. Liu, Comprehensive evalu${ }_{420}^{4}$ ation of deep eutectic solvents in extraction of bioactive natural products, ACS Sustainable Chemistry \& Engineering 4 (4) (2016) 24052411. arXiv:https://doi.org/10.1021/acssuschemeng.6b00091, doi: 10.1021/acssuschemeng.6b00091 URL https://doi.org/10.1021/acssuschemeng.6b00091

[15] M. Ruesgas-Ramón, M. C. Figueroa-Espinoza, E. Durand, Application of n deep eutectic solvents (des) for phenolic compounds extraction: Overview, challenges, and opportunities, Journal of Agricultural and Food Chemistry 65 (18) (2017) 3591-3601, pMID: 28414232. arXiv:https://doi.org/10. 1021/acs.jafc.7b01054, doi:10.1021/acs.jafc.7b01054

$430 \quad$ URL https://doi.org/10.1021/acs.jafc.7b01054

[16] H. Cruz, N. Jordão, P. Amorim, M. Dionísio, L. C. Branco, 口. Deep eutectic solvents as suitable electrolytes for electrochromic devices, ACS Sustainable Chemistry \& Engineering 6 (2) (2018) 2240- 
URL https://doi.org/10.1021/acssuschemeng.7b03684

[17] A. Paiva, R. Craveiro, I. Aroso, M. Martins, R. L. Reis, A. R. C. Duarte, Natural deep eutectic solvents - solvents for the 21st century, ACS Sustainable Chemistry \& Engineering 2 (5) (2014) 1063-1071. arXiv:https: //doi.org/10.1021/sc500096j, doi:10.1021/sc500096j. URL https://doi.org/10.1021/sc500096j

[18] G. García, S. Aparicio, R. Ullah, M. Atilhan, Deep eutectic solvents: Physicochemical properties and gas separation applications, Energy \& Fuels 29 (4) (2015) 2616-2644. arXiv:https://doi.org/10.1021/ef5028873, doi:10.1021/ef5028873. URL https://doi .org/10.1021/ef5028873

[19] Y. Liu, J. B. Friesen, J. B. McAlpine, D. C. Lankin, S.-N. Chen, G. F. Pauli, Natural deep eutectic solvents: Properties, applications, and perspectives, Journal of Natural Products 81 (3) (2018) 679-690, pMID: 29513526. arXiv:https://doi.org/10.1021/acs.jnatprod.7b00945 doi:10.1021/acs.jnatprod.7b00945 URL https : //doi .org/10.1021/acs . jnatprod.7b00945

[20] J. M. Silva, C. V. Pereira, F. Mano, E. Silva, V. I. B. Castro, I. Sá-Nogueira, (1) R. L. Reis, A. Paiva, A. A. Matias, A. R. C. Duarte, Therapeutic role of deep eutectic solvents based on menthol and saturated fatty acids on wound healing, ACS Applied Bio Materials 2 (10) (2019) 4346-4355, pMID: 32030369. arXiv:https://doi.org/10.1021/acsabm.9b00598, doi:10. 1021 /acsabm.9b00598.

URL https : //doi .org/10.1021/acsabm.9b00598

${ }_{460}[21]$ R. B. Leron, A. N. Soriano, M.-H. Li, Densities and refractive indices of the घ deep eutectic solvents (choline chloride+ethylene glycol or glycerol) and their aqueous mixtures at the temperature ranging from 298.15 to $333.15 \mathrm{k}$. 
Journal of the Taiwan Institute of Chemical Engineers 43 (4) (2012) 551 557. doi:https://doi.org/10.1016/j.jtice.2012.01.007.

[22] R. B. Leron, M.-H. Li, High-pressure volumetric properties of 口 choline chloride-ethylene glycol based deep eutectic solvent and its mixtures with water, Thermochimica Acta 546 (2012) 54 - 60. doi:https://doi.org/10.1016/j.tca.2012.07.024. URL http://www.sciencedirect.com/science/article/pii/ S0040603112003681

[23] A. Yadav, J. R. Kar, M. Verma, S. Naqvi, S. Pandey, Densi1 ties of aqueous mixtures of (choline chloride+ethylene glycol) and 475 (choline chloride+malonic acid) deep eutectic solvents in temperature range 283.15-363.15k, Thermochimica Acta 600 (2015) 95 - 101. doi:https://doi.org/10.1016/j.tca.2014.11.028.

10 URL http://www.sciencedirect.com/science/article/pii/ S0040603114005449

${ }_{480}[24]$ A. R. Harifi-Mood, R. Buchner, Density, viscosity, and conductivity of 口 choline chloride+ethylene glycol as a deep eutectic solvent and its binary mixtures with dimethyl sulfoxide, Journal of Molecular Liquids 225 (2017) 689 - 695. doi:https://doi.org/10.1016/j.molliq.2016.10.115 URL http://www.sciencedirect.com/science/article/pii/ S0167732216326204

[25] N. F. Gajardo-Parra, M. J. Lubben, J. M. Winnert, Ángel Leiva, J. F. a Brennecke, R. I. Canales, Physicochemical properties of choline chloride1 based deep eutectic solvents and excess properties of their pseudo-binary mixtures with 1-butanol, The Journal of Chemical Thermodynamics 133 (2019) $272-284$. doi:https://doi.org/10.1016/j.jct.2019.02.010. 
URL http://www.sciencedirect.com/science/article/pii/ S0021961418309996

[26] R. Haghbakhsh, S. Raeissi, Experimental investigation on the volu-

a metric properties of mixtures of the deep eutectic solvent of ethaline and methanol in the temperature range of 283.15 to $323.15 \mathrm{k}$,

The Journal of Chemical Thermodynamics 147 (2020) 106124. doi:https://doi.org/10.1016/j.jct.2020.106124.

口 URL https://www.sciencedirect.com/science/article/pii/ S0021961420300264

[27] R. Haghbakhsh, S. Raeissi, A study of non-ideal mixtures of ethanol and n. the $(1$ choline chloride +2 ethylene glycol) deep eutectic solvent for their volumetric behaviour, The Journal of Chemical Thermodynamics 150 (2020) 106219. doi:https://doi.org/10.1016/j.jct.2020.106219.

URL https://ww.sciencedirect.com/science/article/pii/ S0021961420302883

[28] S. Kaur, A. Gupta, H. K. Kashyap, How hydration affects the microscopic structural morphology in a deep eutectic solvent, The Journal of Physical Chemistry B 124 (11) (2020) 2230-2237, pMID: 32105490. arXiv:https:// doi.org/10.1021/acs.jpcb.9b11753, doi:10.1021/acs.jpcb.9b11753 URL https://doi.org/10.1021/acs . jpcb.9b11753

[29] A. T. Celebi, T. J. H. Vlugt, O. A. Moultos, Structural, thermodynamic, n and transport properties of aqueous reline and ethaline solutions from molecular dynamics simulations, The Journal of Physical Chemistry B

(1) 123 (51) (2019) 11014-11025, pMID: 31794220. arXiv:https://doi.org/ 10.1021/acs.jpcb.9b09729, doi:10.1021/acs.jpcb.9b09729.

URL https://doi .org/10.1021/acs.jpcb.9b09729

[30] B. Doherty, O. Acevedo, Opls force field for choline chloride-based deep eutectic solvents, The Journal of Physical Chemistry B 122 (43) (2018) 99829993, pMID: 30125108. arXiv:https://doi.org/10.1021/acs.jpcb. 
URL https://doi.org/10.1021/acs.jpcb.8b06647

[31] W. L. Jorgensen, D. S. Maxwell, J. Tirado-Rives, Development and testing

1. of the opls all-atom force field on conformational energetics and properties of organic liquids, Journal of the American Chemical Society 118 (45)

525 a (1996) 11225-11236. arXiv:https://doi.org/10.1021/ja9621760, doi: $10.1021 / \mathrm{ja} 9621760$

URL https://doi.org/10.1021/ja9621760

[32] H. G. Petersen, Accuracy and efficiency of the particle mesh ewald method,

घ The Journal of Chemical Physics 103 (9) (1995) 3668-3679. arXiv:https:

//doi.org/10.1063/1.470043, doi:10.1063/1.470043.

URL https://doi.org/10.1063/1.470043

[33] Lindahl, Abraham, Hess, van der Spoel, Gromacs 2021 manual (Jan. 2021). doi:10.5281/zenodo.4457591.

URL https://doi .org/10.5281/zenodo.4457591

[34] M. J. Abraham, T. Murtola, R. Schulz, S. Páll, J. C. Smith, B. Hess, E. Lindahl, Gromacs: High performance molecular simulations through multi-level parallelism from laptops to supercomputers, SoftwareX 1-2 (2015) 19 - 25. doi:https://doi.org/10.1016/j.softx.2015.06.001. \$2352711015000059

[35] L. Martínez, R. Andrade, E. G. Birgin, J. M. Martínez, Packmol: A

a package for building initial configurations for molecular dynamics simulations, Journal of Computational Chemistry 30 (13) (2009) 2157-

a 2164. arXiv:https://onlinelibrary.wiley.com/doi/pdf/10.1002/ jcc.21224, doi:https://doi.org/10.1002/jcc.21224.

URL https://onlinelibrary.wiley.com/doi/abs/10.1002/jcc.21224

[36] G. Bussi, D. Donadio, M. Parrinello, Canonical sampling through velocity rescaling, The Journal of Chemical Physics 126 (1) (2007) 014101. arXiv: 
https://doi.org/10.1063/1.2408420, doi:10.1063/1.2408420

URL https : //doi .org/10.1063/1.2408420

[37] H. J. C. Berendsen, J. P. M. Postma, W. F. van Gunsteren, A. DiNola, J. R. Haak, Molecular dynamics with coupling to an external bath, The Journal of Chemical Physics 81 (8) (1984) 3684-3690. arXiv:https:// doi.org/10.1063/1.448118, doi:10.1063/1.448118. URL https : //doi .org/10.1063/1.448118

[38] I. Pethes, I. Bakó, L. Pusztai, Chloride ions as integral parts of hydrogen bonded networks in aqueous salt solutions: the appearance of solvent separated anion pairs, Phys. Chem. Chem. Phys. 22 (2020) 11038-11044. doi:10.1039/D0CP01806F, URL http://dx.doi .org/10.1039/D0CP01806F

[39] A. Ghoufi, F. Artzner, P. Malfreyt, Physical properties and hydrogena bonding network of water-ethanol mixtures from molecular dynamics simulations, The Journal of Physical Chemistry B 120 (4) (2016) 793-802, pMID: 26743948. arXiv:https://doi.org/10.1021/acs.jpcb.5b11776, doi:10.1021/acs.jpcb.5b11776. URL https://doi .org/10.1021/acs.jpcb.5b11776

[40] M. G. Del Pópolo, G. A. Voth, On the structure and dynamics of ionic liquids, The Journal of Physical Chemistry B 108 (5) (2004) 1744-1752. arXiv:https://doi.org/10.1021/jp0364699, doi:10.1021/jp0364699. URL https: //doi .org/10.1021/jp0364699

[41] M. H. Kowsari, S. Alavi, M. Ashrafizaadeh, B. Najafi, Molecular dynamn ics simulation of imidazolium-based ionic liquids. i. dynamics and diffusion coefficient, The Journal of Chemical Physics 129 (22) (2008) 224508. arXiv:https://doi.org/10.1063/1.3035978, doi:10.1063/1.3035978

575 URL https://doi.org/10.1063/1.3035978

[42] S. L. Perkins, P. Painter, C. M. Colina, Molecular dynamic simulations and vibrational analysis of an ionic liquid analogue, The Journal of Physical 
[43] S. Prabhakar, H. Weingärtner, The influence of molecular association on diffusion in the system methanol - carbon tetrachloride at $25^{\circ} \mathrm{C}$, Zeitschrift für Physikalische Chemie 137 (1) (1983) 1-12. doi:doi:10.1524/zpch. 1983.137.1.001.

585 URL https: //doi.org/10.1524/zpch.1983.137.1.001

[44] R. L. Hurle, A. J. Easteal, L. A. Woolf, Self-diffusion in monohydric alcohols under pressure. methanol, methan $(2 \mathrm{~h})$ ol and ethanol, J. Chem. Soc., Faraday Trans. 181 (1985) 769-779. doi:10.1039/F19858100769.

URL http://dx.doi.org/10.1039/F19858100769 